\title{
Plan de exportación de mole con pollo deshebrado, al mercado de Shangái, China
}

Plan of export of mole with shredded chicken, to the market of Shangái, China.

$$
\text { González Salas Miguel Ángel }{ }^{1 凶} \text {, Mendo Muñoz Rubén de la Paz }{ }^{1} \text {, Pérez Aquino }
$$

Francisco Javier ${ }^{1}$

${ }^{1}$ Facultad de Ciencias Biológico Agropecuarias campus Tuxpan. Universidad Veracruzana
${ }^{凶}$ Autor para correspondencia: miguegonzalez@uv.mx

Recibido: $16 / 08 / 2016$

Aceptado: 19/11/2016

\section{RESUMEN}

La cocina mexicana es considerada una de las más exquisitas, debido a su excelente combinación de sabores, texturas y olores no conoce fronteras además China se ha dejado encantar por su sabor inconfundible. La apertura de China al mundo ayudó a que los productos mexicanos fueran más fáciles de exportar. Considerando lo anterior se diseñó un Plan de exportación que permitiera ingresar el mole con pollo deshebrado al mercado de Shanghái, China. Dentro del estudio de Mercado se estima una demanda de Alimentos Procesados en China a una Tasa Media de Crecimiento Anual del 7.5\% entre 2012- 2020, siendo una ventaja para el proyecto. De manera general y con relación a la hipótesis de este proyecto concluimos que es viable exportar "Mole con pollo deshebrado" de la ciudad de Papantla, Veracruz, al mercado de Shanghái.

Palabras clave: Mole, Shangai, comercialización

\begin{abstract}
Mexican cuisine is considered one of the most exquisite, due to its excellent combination of flavors, textures and smells knows no borders and China has been enchanted by its unmistakable flavor. The opening of China to the world helped make Mexican products easier to export. Considering the above, an Export Plan was designed to allow the mole with chicken to be introduced to the Shanghai market, China. Within the Market study, a demand for Processed Foods in China is estimated at an Annual Average Growth Rate of $7.5 \%$ between $2012-2020$, being an advantage for the project. In general and in relation to
\end{abstract}


the hypothesis of this project, we conclude that it is feasible to export "mole with deforested chicken" from the city of Papantla, Veracruz, to the Shanghai market.

Keywords: Mole, Shanghai, marketing

\section{INTRODUCCIÓN}

Con la llegada de los españoles en el siglo XVI, surge una amplia gama de recetas culinarias, donde se fusionaron dos culturas la española y la azteca; la leyenda del mole cuenta que es una creación de una conciliación cultural que no surgió de la noche a la mañana, ni se creó por una sola persona. El mole nace como cocina conventual en el monasterio de Santa Rosa, en Puebla de los Ángeles, en el Siglo XVII, nace entonces para deleite del mundo el mole poblano, plato legendario y barroco confeccionado con alrededor 30 ingredientes. China es un país con mayor crecimiento en todos los ámbitos: político, económico y cultural. Actualmente es el segundo socio comercial de México y se precisa que entre 1999 al 2014 su inversión Extranjera Directa (IED) alcanzó los 309.71 millones de dólares. Hoy el 2\% de las exportaciones mexicanas son hacia China. En el 2013 los acuerdos que se lograron de la visita de Xi Jiping al país, fue un impulso económico. México y China destrabaron a acuerdos principalmente en sectores de la industria textil, vestido, calzado y alimentos". (El economista, 2013).

La producción en el 2012 de alimentos procesados en México fue de 123,954 millones de dólares. Se estima que tenga un crecimiento anual para el periodo del 2012-2020, del 7.6\%. En
2011 la industria de conservación de frutas, verduras, y guisos concentró el $4.4 \%$ de participación del valor total de la producción. El consumo en el 2012 fue de 124,983 millones de dólares. En el periodo 2012-2020 se pronostica que el consumo incremente anualmente el 7.4\% (Martínez, 2013). Las Exportaciones Mexicanas de alimentos procesados alcanzaron los 7,642 millones de dólares en el periodo 20062012 y tuvieron un incremento anual del 12\%. En 2012 las exportaciones mexicanas de alimentos procesados alcanzaron un valor de 7,642 $\mathrm{md}$, en el periodo 2006-2012 las exportaciones crecieron a un $12 \%$ anual (Martínez, 2013). Los principales destinos de los productos alimenticios Mexicanos, en el 2012 fueron a EE.UU., con un valor de 5,235 millones de dólares, mientras que a Hong Kong alcanzo un valor de 75 millones de dólares. Las preparaciones alimenticias con Código del Sistema Armonizado 2106 tuvieron una participación del $4 \%$ en el comercio Exterior (Martínez, 2013). En la región de Papantla el problema es que el mole no cuenta con valor agregado y se comercializa a través de tiendas de abarrotes y mercado local. La exportación de mole con pollo deshebrado es una opción para generar empleo, utilidades y producción, en la ciudad de Papantla. En este orden de ideas se plantea el objetivo siguiente: Diseñar un plan de exportación que permita tener la perspectiva de ingresar 
el producto mole con pollo deshebrado al mercado de Shanghái, China.

\section{MATERIALES Y MÉTODO}

La empresa "Alimentos Papantecos. S.A. de C.V." se ubica en el municipio de Papantla estado de Veracruz, debido a que en éste estado se tienen las mejores condiciones tanto de materia prima y del transporte. La planta será localizada un terreno urbano de 3250 metros cuadrados, ubicado en la calle Girasoles sin número, en la colonia Magisterial Xanath en Papantla de Olarte, Veracruz. La empresa se dedica a la elaboración de mole con pollo deshebrado, mediante el uso de producción mecanizada y mano de obra. Dentro de la maquinaria que se encuentran: molinos, freidoras, parrillas, envasadora automática, Autoclave para esterilizar los productos.

El mercado potencial es China, cuya población es de 1, 357, 380,000 de Habitantes 2013 compuesta de una población urbana del $51.8 \%$ mientras que la rural de un $48.2 \%$ que está conformada de una población Masculina de $51.7 \%$ y $48.2 \%$ femenina, mientras que el $1.70 \%$ representa la población de Shanghái de 23,019, 196 habitantes el cual es el mercado al que se pretende llegar. El crecimiento natural es de $0.5 \%$ (Banco Mundial, 2013). En el ranking Mundial es la primera en exportaciones y la segunda en importaciones, de acuerdo a sus

indicadores económicos, sus exportaciones fueron de $2048 \quad 714$ billones de dólares en el 2012 y sus importaciones fueron de $1,818,405$ billones de dólares en el 2012. La república popular China tiene una participación Mundial del $11.3 \%$ en exportaciones $y$ un $9.7 \%$ en importaciones (OMC, 2012). Cuenta con 6 principales aeropuerto internacionales los cuales son Beijing, Guangzhou Baiyun, Hong Kong, Pudong Shanghái, Shanghái Hongqiao, Macao (Aeropuertos del Mundo, 2014).

Cuando se hace negocios con China es importante conocer los diferentes puertos. Uno de los más importantes es el puerto de Shanghái lo cual lo consideran la puerta de ingreso. El puerto de Dalian está situado al noroeste de lo cual es ideal para el comercio entre el sudeste Asiático, Norte América y Europa (INPECHI, 2010). Para llegar a los consumidores chinos existen diferentes tipos de medios publicitarios de los cuales son los siguientes. Las principales televisoras son Anhui TV (AHTV), Televisión central de China (CCTV), Beijing TV (BTV), Tom Group Limited, Sichuan TV, Hunan TV, Shanghái Media Group (SMG), Hubei TV (HBTV), el 95\% de la población china ve televisión (Grupo Santander, 2014). La prensa china que comprende Diarios y revistas es una gran medio publicitaria entre los que mayor impacto es el Diario de china, Liberty Times, Diario del pueblo, Diario de Cantón, Pekín Times, Beijing Daily (Grupo Santander, 2014). Otro medio de comunicación es el Radio, es un muy económico para llegar a varios tipos de consumidores entre los que

destacan la Radio de China Internacional, Radio nacional de China, Broadcasting Corporation of China, Beijing Broadcasting Network, Radio Guangdon, Lanzhou Radio Group, Shanghái Media Group, Tianjin People's Broadcasting Station (TPBS) (Grupo Santander, 2014). China registro un consumo de 1,044 millones de dólares 
con un crecimiento del $8.4 \%$ en el 2012 , se estiman que entre el 2012 al 2020 tenga un crecimiento anual del $11.5 \%$. (Global Insight). La economía China tiene un alto crecimiento, en cuanto a sus gustos por la cocina tradicional y preferencias alimentarias son muy importantes para ellos. La comida internacional como son la comida rápida, productos de alta calidad está ganando una popularidad e influencia entre los Habitantes (Proecuador, 2014). Las actuales generaciones que tiene un rango de edad entre los 25-69 años representan el $57.9 \%$ de los habitantes en China, tienen un poder adquisitivo muy altos y dispuestos a probar diferentes productos, estos consumidores chinos están adoptando hábitos de consumo semejantes a otros patrones de Estados unidos, Europa, y Asia (Proecuador, 2014). Se estima que un porcentaje de las ventas no superior al $4 \%$ son productos importados $\mathrm{y}$ de acuerdo a Especialista de Inteligencia de Mercados en promedio el $39 \%$ de los habitantes chinos gastan sus ingresos en alimentación (Nieto, 2011). Los problemas y seguridad alimentaria con algunas marcas nacionales ha hecho que los consumidores esten más convencidos de adquirir productos importados porque tienen la certeza de que son de mayor calidad e inocuos (Proecuador, 2014).

\section{CONCLUSIONES}

Una vez ejecutado el plan de exportación de mole con pollo deshebrado de la ciudad de Papantla, Veracruz a la ciudad de Shanghái, China podemos decir que se cuenta con la información necesaria para ingresar a su Mercado para lo cual fue necesaria una investigación cualitativacuantitativa que permitió detallar una base real para el proyecto de exportación. Dentro del estudio de Mercado concluimos que se estima una demanda de Alimentos Procesados en China a una Tasa Media de Crecimiento Anual del $7.5 \%$ entre 2012- 2020, lo que es una ventaja para el proyecto. La empresa pretende comercializar un guiso mexicano mole con pollo deshebrado a base de ingredientes tales como chiles, plátano, tortilla, condimentos, el empaque es en bolsas flexibles o envases pouch, en una presentación de 230 gramos.

El consumo aparente del Mole con pollo deshebrado es de 533,124 productos al año, a un precio de venta de exportación de $\$ 66.80$ MXN calculado con el Incoterms CIF (Costo, Seguro, y Flete) equivalente a $\$ 4.54$ USD y \$28.09 yuanes (CNY) por bolsa de mole con pollo deshebrado, el incremento en el precio para los demás años fue del $3.8 \%$ anual de acuerdo a la inflación. El canal de comercialización del mole se pretende que se realice a través de un intermediario comercial para una rápida distribución, y la promoción es por medio de marketing digital los cuales son económicos y de mayor impacto actualmente.

\section{LITERATURA CITADA}

Baca G. 2001. Evaluación de proyectos. (5 ed.). McGraw-Hill. México, D.F.

El Economista. 2013. México y

\section{China}

logran acuerdos de Asociación

Estratégica. 1 d

Consultado

el $\quad 9 \quad$ e

http://eleconomista.com.mx/industr

ias/

2013/06/04/mexico-china-logran- 
acuerdo-

asociacion-estrategica

INPECHI. 2010. Principales Puertos en China. Consultado el 19 de Mayo de 2014, de https://inpechi.org/principalespuertos-en-china.html

Marco Beteta. 2012. "La comida mexicana en China”. Consultado el 18 de Mayo de 2014, de http://www.marcobeteta.com/ blog/\%E2\%80\%9Clos-embajadores-demexico-en-el-mundo\%E2\%80\%9D-uncaso-de-exito-la-comida-mexicana-enchina/\#comments

McGraw-Hill. $\quad$ 1987. Biblioteca Práctica de Negocios, Tomo VII, Mercadotecnia. (1987). Editorial McGraw-Hill. México.

McGraw-Hill.1987 Biblioteca Práctica de Negocios, Tomo IV, Administración Financiera. Editorial McGraw-Hill.

México.

McGraw-Hill, 1992. Biblioteca Práctica de Negocios, Tomo II, Administración de Operaciones. McGraw-Hill. México.

Miranda, J. 2005. Gestión de Proyectos: Evaluación Financiera Económica Social Ambiental. Bogotá:

$\mathrm{MM}$

Ramírez P, 2007. Contabilidad Administrativa, Libros McGraw Hill, Octava Edición, México. 
Copyright (c) 2016 Miguel Ángel G onzález Salas, Rubén de la Paz Mendo Muñoz y

Pérez Aquino Francisco Javier

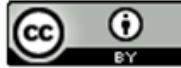

Este tex to está protegido por una licencia licencia Creative Commons 4.0

Usted es libre para Compartir —copiar y redistribuir el material en cualquier medio o form ato-y Adaptar el documento —remezclar, transformar y crear a partir del material- para cualquier propósito, incluso para fines comerciales, siempre que cumpla 1a condición de:

Atribución: Usted debe dar crédito a la obra original de manera adecuada, proporcionar un enlace a la licencia, e in dicar si se han realizado cambios. Puede hacerlo en cualquier form a razonable, pero no de form a tal que sugiera que tiene el apoyo del licenciante o 10 recibe por el uso que hace de la obra.

Resumendelicencia - Textocompletodelalicencia 